\title{
Adenosine levels in the exhaled breath condensate: a potential surrogate marker of airway inflammation
}

\section{To the Editor:}

We would like to congratulate HUSZAR et al. [1] on their important and meticulous study demonstrating elevated adenosine levels in the exhaled breath condensate of atopic asthmatic subjects compared to nonatopic controls. Their findings are in agreement with and somewhat complementary to previous data obtained from bronchoalveolar lavage fluid of patients with asthma and chronic obstructive pulmonary disease [2], thus adding to the notion that adenosine may have a pathogenic role in chronic inflammatory disorders of the airways [3]. Unfortunately, our knowledge on the role of adenosine in physiological and pathological conditions remains limited by the availability of potent and selective adenosinereceptor antagonists for use in humans.

In relation to the findings of the present study, it is important to emphasise that these atopic asthmatics were all sensitised to grass pollen and all studied during the grass pollen season. Natural exposure to aeroallergens is likely to modulate the level of airway inflammation not only in asthma but also in hay fever patients. We have repeatedly shown that nonasthmatic individuals with allergic rhinitis also exhibit features of active inflammation in the lower airways which deteriorates during natural allergen exposure [4, 5].

It is therefore likely that the results of the study by HUSZAR et al. [1] could also be interpreted as a response to natural allergen exposure reflecting inflammatory changes occurring at airway levels. Indeed, the pioneering work by MANN et al. [6] clearly demonstrated a significant increase in the plasma levels of adenosine following allergen challenge in subjects with atopic asthma. Although the inclusion of an atopic control group would have enhanced the quality of the paper by Huszar et al. [6], an important implication of these findings is that adenosine levels in the exhaled breath condensate could be valuable in assessing disease activity in relation to airway inflammation. This will obviously require rigorous testing in future long-term studies where seasonal changes in exhaled breath condensate adenosine levels are clearly related to natural allergen exposure/avoidance.

\section{Spicuzza, G.U. Di Maria, R. Polosa}

Dipartimento di Medicina Interna e Specialistica, AscoliTomaselli Hospitals-University of Catania, Catania, Italy.

\section{References}

1. Huszár É, Vass G, Vizi É, et al. Adenosine in exhaled breath condensate in healthy volunteers and in patients with asthma. Eur Respir J 2002; 20: 1393-1398.

2. Driver AG, Kukoly CA, Ali S, Mustafa SJ. Adenosine in bronchoalveolar lavage fluid in asthma. Am Rev Respir Dis 1993; 148: 91-97.

3. Polosa R. Adenosine-receptor subtypes: their relevance to adenosine-mediated responses in asthma and chronic obstructive pulmonary disease. Eur Respir J 2002; 20: 488-496.
4. Polosa R, Ciamarra I, Mangano G, et al. Bronchial hyperresponsiveness and airway inflammation markers in nonasthmatics with allergic rhinitis. Eur Respir J 2000; 15: 30-35.

5. Polosa R, Li Gotti F, Mangano G, Mastruzzo C, Pistorio MP, Crimi N. Monitoring of seasonal variability in BHR and sputum cells count in nonasthmatic subjects with rhinitis and effect of specific immunotherapy. Clin Exp Allergy 2003; (in press).

6. Mann JS, Holgate ST, Renwick AG, Cushley MJ. Airway effects of purine nucleosides and nucleotides and release with bronchial provocation in asthma. J Appl Physiol 1986; 61: $1667-1676$.

\section{From the authors:}

It is a pleasure to read the appreciation shown by L. Spicuzza and colleagues for our recent study on adenosine in exhaled breath condensate (EBC-adenosine).

We would like to comment on the possibility of using adenosine as a marker to assess the degree of airway inflammation. We agree with the comments made by L. Spicuzza and colleagues with regard to our results showing that EBCadenosine levels are related to the degree of airway inflammation and are in line with previous findings, suggesting that adenosine may be a nonspecific marker of airway inflammation [1]. In particular, it is worth noting that in the study by DRIVER et al. [1], no chronic obstructive pulmonary disease patients were included, only asymptotic smokers along side asthmatic patients. In a preliminary study we have shown that EBC-adenosine is also elevated in patients with cystic fibrosis, confirming that elevated adenosine levels may be a nonspecific indicator for ongoing airway inflammation [2].

Interestingly, not only is the increase in airway adenosine concentration related to other markers of airway inflammation but airway hyperresponsiveness to adenosine monophosphate also reflects the intensity of airway inflammation. Because both the release and indirect action of adenosine have been shown to be related to the number and/or activation of "primed" mast cells and other inflammatory cells present in the airways this could explain the observed relationships [1-5]. It also seems to be obvious that the enhanced level of adenosine in the airways would lead to potentiated airway obstruction provoked by diverse bronchoconstrictor agents in asthma [6, 7].

Our results partly confirm the statement of the correspondents that exposure to aeroallergens may modulate airway inflammation in asthmatic patients. We found elevation in both EBC-adenosine concentrations and exhaled nitric oxide (eNO) levels in patients with worsening asthmatic symptoms. However, only eNO levels, not adenosine concentrations, were higher in patients in a stable condition than in healthy controls. This finding suggests that eNO may be a more sensitive marker of airway inflammation than EBC-adenosine in atopic asthmatics, showing even the hidden inflamed processes in the airways.

Furthermore, the notion concerning the potential effect of allergic rhinitis on mediator levels in the lower airways seems 
to be correct. In a pilot study, we measured EBC-adenosine levels in eight nonasthmatic patients with allergic rhinitis. At the time of the measurement all patients were exposed to natural allergens and had symptoms of rhinitis. Adenosine concentrations were significantly higher in samples from these patients than in samples from healthy subjects. This result confirms that active allergic inflammation, either of the upper or lower airways, may result in elevation in EBC-adenosine concentration as suggested. Furthermore, when EBC was collected with nasal inhalation adenosine levels were higher than in samples obtained with oral inhalation, suggesting that nasally produced adenosine may enter the lower airways which may, at least in part, be responsible for increases in the adenosine levels [8].

Finally, we agree with L. Spicuzza and colleagues that there is a need for further prospective studies on this topic. We believe these studies need to assess changes in the concentration of adenosine in exhaled breath condensate and also evaluate the relationship between adenosine in exhaled breath condensate and the degree of allergen exposure or deterioration in airway inflammation. Justification of the possible use of the concentration of adenosine in exhaled breath condensate to monitor chronic or acute airway inflammation also requires further investigation.

\section{É. Huszár, I. Horváth}

Dept of Pathophysiology, National Korányi Institute for Tuberculosis and Pulmonology, Budapest, Hungary.

\section{References}

1. Driver AG, Kukoly CA, Ali S, Mustafa SJ. Adenosine in bronchoalveolar lavage fluid in asthma. Am Rev Respir Dis 1993; 148: 91-97.

2. Barát E, Huszár É, Vass G, Csiszér E, Valyon M, Horváth I. Measurement of natrium chloride and adenosine concentration in exhaled breath condensate. Eur Respir J 2002; 20: Suppl. 38, 281s.

3. Polosa R, Ciamarra I, Mangano G, et al. Bronchial hyperresponsiveness and airway inflammation markers in nonasthmatics with allergic rhinitis. Eur Respir $J$ 2000; 15: 30-35.

4. Polosa R, Holgate ST. Adenosine bronchoprovocation: a promising marker of allergic inflammation in asthma? Thorax 1997; 52: 919-923.

5. van den Berge M, Meijer RJ, Kerstjens HA, et al. PC20 adenosine $5^{\prime}$-monohosphate is more closely associated with airway inflammation in asthma than PC20 methacholine. Am J Respir Crit Care Med 2000; 163: 1546-1550.

6. Huszár É, Horváth I, Barát E, Herjavecz I, BöszörményiNagy Gy, Kollai M. Elevated circulating adenosine level potentiates antigen-induced immediate bronchospasm and bronchoconstrictor mediator release in sensitized guinea pigs. J Allergy Clin Immunol 1998; 102: 687-691.

7. Csoma Zs, Vizi É, Huszár É. Post-exercise changes in FEV1 values and in adenosine concentrations in exhaledbreath condensate in healthy subjects and patients with exerciseinduced asthma. Eur Respir J 2002; 20: Suppl. 38, 290s.

8. Vass G, Huszár É, Barát E, et al. Comparison of nasal and oral inhalation during exhaled breath condensate collection. Am J Respir Crit Care Med 2002; 167: 850-855.

\section{Exhaled breath temperature in airways disease}

\section{To the Editor:}

It was with interest that we read the study of PAREDI et al. [1] which reports a slower rise in exhaled breath temperature in patients with chronic obstructive pulmonary disease (COPD). It is intriguing to think that altered airway heat transfer may provide a noninvasive marker of airways inflammation or remodelling. However, heat transfer in the airway has long been known to be a complex process and we feel this study leaves important questions unanswered.

The authors hypothesise that patients with COPD have alterations in bronchial blood flow that affect the rise in exhaled air temperature. Heat transfer in the airways in the context of respiratory disease was studied by WALKER et al. [2] in 1961, and since in COPD [3], cystic fibrosis [4] and thermally induced asthma [5]. There is still controversy over the relative roles of the upper airway, bronchial circulation and pulmonary circulation in airway heat exchange. Under conditions of high ventilation, the work of BAILE et al. [6], Solway et al. [7] and, more recently, SERIKOV and Fleming [8] showed pulmonary circulation to be the dominant heat source to the airways. Furthermore, using invasive measurements of intra-airway temperature, MCFADDEN et al. [9] showed that airways down to subsegmental level are actively involved in heat exchange only at high minute ventilation with extremely cold inspired air. In contrast, when breathing indoor room air at normal tidal flow rates, virtually all heat transfer occurs in the upper airway (above the glottis) [10]. It has therefore yet to be established whether changes in bronchial blood flow caused by disease are a significant determinant of breath temperature under normal ambient conditions. In the study of PAREDI et al. [1], subjects were respiring warm room air $\left(21-23^{\circ} \mathrm{C}\right)$ at low flow rates $\left(10 \mathrm{~L} \cdot \mathrm{min}^{-1}\right)$. Previous work would suggest that the airway below the glottis (which the authors seek to test) would not be contributing significantly to heat exchange under these conditions.

Regarding the methodology of the temperature washout technique, the authors acknowledge the extreme sensitivity of the rate of temperature rise to expiratory flow rate but do not report the method of flow targeting or indeed the flow rates achieved in controls versus COPD groups. Expiratory flow patterns rather than airway heat transfer may therefore contribute to the differences seen between the groups and are crucial to the interpretation of the temperature washout data. Finally, heat is consumed in two ways during inspiration: $\sim 25 \%$ of the energy is used in heating the air (convective) and $75 \%$ in evaporating moisture from the mucosal surface to humidify the air stream (evaporative). On expiration, the reverse of both processes occurs, namely, convective cooling and condensation of water vapour on the mucosa. This dominance of energy transfer through evaporation and condensation suggests that attempts to characterise the thermodynamic performance of the airways by temperature measurement alone, without accompanying humidity measurements, may be misleading.

As with all new noninvasive breath measurements, it is important that methods and protocols are standardised and 